\title{
258 Immunology of the pharyngeal lymphoid tissue
}

A B lymphocytes proliferate in active follicles.

B T lymphocytes secrete lymphokines which act locally to control the inflammatory response.

C B lymphocytes synthesize IgA secretory antibodies.

D Macrophages are involved in presenting antigen to $T$ lymphocytes.

E T lymphocytes are required for cell-mediated immunity.

\section{Anatomy of the parotid gland}

A Develops as an ectodermal diverticulum of the primitive oral cavity.

B Is covered on its outer aspect by a thickened layer of deep cervical fascia.

C Occupies the space between the mastoid process posteriorly and the ascending ramus of the mandible anteriorly.

D The facial nerve trunk is deep to the retromandibular vein.

E Secretomotor fibres to the gland travel in the auriculotemporal nerve. 